\title{
LEKSIKON KEKERABATAN ETNIK MELAYU BANGKA DI KOTA PANGKALPINANG
}

\section{LEXICONS KINSHIP BANGKANESE MALAY ETHNICS IN PANGKALPINANG DISTRICT}

\author{
Rahmat Muhidin \\ Balai Bahasa Sumatera Selatan \\ Jalan Seniman Amri Yahya, SU I, Jakabaring, Kota Palembang \\ Naskah diterima tanggal 12 Agustus 2019 \\ Naskah direvisi terakhir tanggal 6 Desember 2019
}

\begin{abstract}
This is research aims to identity and classify the kinship lexicon then explain the role and meaning in Bangkanese Malay greetings. The research used descriptive method. The technique used was ethnographical interview. Bangkanese Malay ethnic in communicating either in nuclear family based on matchmaking or bloodline (offspring). That research result showed that the role and meaning of lexicon kinship dislayed that the people considered as close relatitive are family. Family relation is both consanguine and afinal. It is categorized into ego aligned, over ego, and below ego.
\end{abstract}

Keywords: kinship, consanguine, afinal

\begin{abstract}
Abstrak
Penelitian ini dilakukan untuk menjelaskan identitas dan mengklasifikasi leksikon kekerabatan dengan menjabarkan peran dan makna sapaan bahasa Melayu Bangka. Penelitian ini menggunakan metode deskriptif. Teknik pengambilan data dengan menggunakan wawancara yang berkaitan secara etnografi. Hasil kajian leksikon kekerabatan bahasa Melayu Bangka di Kota Pangkalpinang adalah sebagai berikut: Etnik Melayu Bangka dalam komunikasi dalam keluarga inti (keluarga batih) berdasarkan pada pertalian darah dan hubungan karena perkawinan. Kategori hubungan itu dapat dikelompokkan menjadi: hubungan sejajar ego/pribadi, di atas ego, dan di bawah ego.

Kata Kunci: kekerabatan, hubungan pertalian darah, hubungan perkawinan
\end{abstract}

\section{PENDAHULUAN}

Hubungan kekeluargaan dalam masyarakat pada umumnya ditandai dengan pemakaian kosakata atau leksikon tertentu, seperti: nenek, kakek, kakak, adik, bapak, ibu dan sebagainya yang dapat dilihat pada garis keturunan atau melalui perkawinan pada suatu masyarakat. Kecenderungan ini dapat diperhatikan lebih jauh dengan cara menghubungkan budaya masyarakat tertentu sehingga tecermin kaitan kekeluargaan dengan menyebut seseorang.

Leksikon atau istilah kekerabatan menurut antropolog dapat dikelompokkan para amenjadi tiga bagian yaitu: (1) cara pemakaian, (2) unsur-unsur bahasa, dan (3) jumlah kerabat yang diklasifikasikan. Bila dilihat dari cara pemakaian, dapat dibedakan menjadi dua bagian leksikon kekerabatan, yakni: menyapa dan menyebut. Menyapa dipakai untuk memanggil seseorang bila berhadapan secara langsung. Menyebut, digunakan untuk memanggil seseorang bila berhadapan dengan orang lain atau berbicara tentang orang ketiga. Contoh: Ipar, mau ke mana? (Karouw, 2011).

Jumlah kerabat yang diklasifikasikan memiliki arti hubungan kekerabatan lain yang dikelompokkan menjadi dua yakni keturunan langsung dan sejajar. Keturunan langsung berhubungan dengan garis vertikal dalam pohon keluarga dan garis horisontal (paman dan bibi). Bila dilihat dari cara pemakaian dapat dibedakan menjadi dua 
bagian leksikon kekerabatan yakni: menyapa dan menyebut. Menyapa dipakai untuk memanggil seseorang bila berhadapan secara langsung. Menyebut digunakan untuk memanggil seseorang bila berhadapan dengan orang lain atau berbicara tentang orang ketiga.

Istilah kekerabatan atau dengan kata lain leksikon kekerabatan atau kosakata kekerabatan suatu bahasa akan muncul karena adanya kebutuhan untuk menyatakan kedudukan diri seseorang secara komunikatif dalam suatu keluarga. Hubungan ini akan dinamakan sekerabat apabila ada pertalian darah (pertalian langsung) dan pertalian perkawinan (pertalian tidak langsung).

Kajian ini dapat dianalisis secara sosiolonguistik dengan tetap memperhatikan sosial budaya masyarakat penggunanya. Tinjauan ini diperlukan karena dalam menggali kaidah-kaidah yang berlaku pada masyarakat memerlukan kejelian untuk mengulas kaidah-kaidah berbahasa seringkali berhubungan dengan situasi, kondisi, dan sosial budayanya.

Istilah kekerabatan menurut Lounsbury (dalam Leech, 1981) dapat dijelaskan menurut jenis kelamin, generasi, dan garis keturunan. Ia mencontohkan kata ayah dan paman untuk laki-laki, sedangkan kata ibu dan bibi untuk perempuan. Leksikon kekerabatan dikelompokkan menjadi tiga bagian, yaitu: generasi di atas ego, (2) generasi di bawah ego, dan (3) generasi sejajar ego. Dalam pengertian ini, ego bermakna diri sendiri dan itu berarti hubungan kekerabatan lain yang dibagi dua yakni garis keturunan langsung dan sejajar. Keturunan langsung berhubungan dengan garis vertikal dalam pohon keluarga dan garis horisontal (paman dan bibi). Pendapat Burling (1970) membagi kekerabatan dalam hubungan darah (kongsanguinal) yakni saudara kandung laki-laki atau perempuan ego sedangkan hubungan karena pernikahan (afinal) yaitu saudara tiri laki-laki dan saudara tiri perempuan. (dalam Femmy Lumempouw, 2013)
Berdasarkan pemaparan pada latar belakang tersebut di atas, maka masalah penelitian ini adalah sebagai berikut:

(1) Apa hubungan peran dan makna leksikon kekerabatan pada masyarakat pengguna bahasa Melayu Bangka di Kota Pangkalpinang?

(2) Leksikon kekerabatan apa saja yang digunakan penutur bahasa Melayu Bangka dalam menyapa dan berinteraksi antarkeluarga?

Adapun tujuan penelitian ini dilakukan adalah sebagai berikut:

(1) Mendeskripsikan, mengidentifikasi, dan mengklasifikasi leksikon kekerabatan masyarakat pengguna bahasa Melayu Bangka di Kota Pangkalpinang.

(2) Mendeskripsikan hubungan peran dan makna leksikon kekerabatan masyarakat pengguna bahasa Melayu Bangka di Pangkalpinang.

Pelaksanaan penelitian ini menggunakan berbagai literatur sebagai bahan pendukung dan pembanding. Literatur yang dimaksud sebagai bahan tinjauan pustaka adalah sebagai berikut.

Karamoy (1997) mengungkapkan kata-kata sapaan kekerabatan dalam bahasa Tontemboan mengikuti pola-pola atau sistem kekerabatan. Folley (1997) menyatakan penelitiannya dengan mengungkapkan hubungan sistem kekerabatan dalam Anthropological Linguistics tentang kekerabatan sedarah pada bahasa Watam. Kamal, dkk (1990) menulis tentang arti dan bentuk sapaan bahasa Iban, ragam bahasa Iban, dan jenis kata bahasa Iban di Kalimantan Barat.

Hasil penelitian Karouw (2009) mengungkap penutur masyarakat Tombulu dengan memilah kata-kata kerabat yang bersifat konsanguinal (hubungan darah) dan bersifat afinal (hubungan karena pernikahan). Beliau juga masih memperhatikan jenis kelamin, tingkat generasi, garis keturunan, dan umur.

Pendapat pakar lain Hoijer (1954) menyatakan terkait hal ini menghubungkannya dengan bahasa, tidak 
hanya berfungsi sebagai sarana untuk melaporkan pengalaman, tetapi berfungsi juga sebagai sarana membentuk pengalaman bagi penuturnya.

Folley (1997) menyebutkan istilah atau leksikon kekerabatan pada kajian kekerabatan dari persepsi universal. Seiring pendapat Malinowski, Folley menyatakan bahwa asal-usul kekerabatan berawal dari keluarga inti atau keluarga batih. Lebih lanjut, ia menekankan pada kekerabatan yang didasarkan pada perjodohan dan reproduksi. Robin Fox dalam (Karouw, 2011) mengungkapkan bahwa kekerabatan merupakan hubungan sederhana dalam sebuah keluarga yang berwujud hubungan pribadi karena pertalian darah/keturunan atau perkawinan. Dalam hubungannya dengan hal tersebut, Folley (1997) menggarisbawahi bahwa bahasa digunakan dalam struktur sosial yang dikaitkan dengan konteks budaya karena mencari makna yang terkandung di balik pemakaian bahasa tersebut.

\section{METODE PENELITIAN}

Penelitian ini dilakukan dengan metode deskriptif kualitatif dengan prosedur yang dilalui berupa pengungkapan data tertulis yang diperoleh melalui wawancara. Selain itu, pemerolehan data dengan studi pustaka atau studi literatur yang diperoleh dari berbagai sumber.

Pengambilan data dengan wawancara merupakan data yang bersifat etnografis. Untuk memudahkan proses penelitian di lapangan, pengumpulan data di lapangan dilakukan dengan mengacu pada sistem kekerabatan agar tidak terjadi penyimpangan atau lompatan pertanyaan dari satu generasi ke generasi lainnya. Selanjutnya, peneliti menanyakan kepada informan dengan merujuk langsung pada status kekerabatan, misalnya kakak atau adik informan. Analisis dengan mengidentifikasi dan mengklasifikasi sistem kekerabatan masyarakat penutur Bahasa Melayu Bangka di Pangkalpinang.

\section{HASIL DAN PEMBAHASAN}

Berdasarkan pengambilan data yang diperoleh dari studi pustaka dan penelitian di lapangan, leksikon atau istilah kekerabatan etnik Melayu Bangka di Kota Pangkalpinang dapat dideskripsikan sebagai berikut. Pada dasarnya, orang-orang yang memiliki hubungan darah pada umumnya orang-orang terdekat dalam kesehariannya mempunyai kaitan keluarga. Wujudnya dapat berupa hubungan yang bersifat konsanguinal dan hubungan afinal. Penjelasan mengenai kedua hal tersebut dapat dikelompokkan berdasarkan menurut jenis kelamin, tingkat generasi, garis keturunan, dan umur.

1.1 Leksikon kekerabatan yang digunakan masyarakat etnik Melayu Bangka dalam menyapa dalam masyarakat sebagai pengguna bahasa Melayu Bangka dialek Pangkalpinang

1.1.1 Leksikon kekerabatan yang bersifat konsanguinal

Leksikon kekerabatan yang bersifat konsanguinal merupakan hubungan kekerabatan yang mempunyai hubungan darah atau keturunan. Hubungan ini dapat dijelaskan dalam leksikon kekerabatan sebagai berikut:

[abang] kakak laki-laki

[bang] kakak laki-laki

[ayuk] kakak perempuan

[yuk] kakak perempuan

[adek] adik laki-laki atau adik perempuan

[dek] adik laki-laki atau adik perempuan

[bak] ayah

[bapak] ayah

[ayah] ayah

[atok] kakek

[tok] kakek

[kakek] kakek

[kek] kakek

[ninek] nenek

[nek] nenek

[mak] ibu

[ibu] ibu

[sepupu] anak dari saudara ayah atau ibu

[keponakan] anak dari kakak atau adik ego/saya

[anak] anak dari ego/saya (sebagai orang tua)

[nak] anak dari ego/saya (sebagai orang tua)

[сиси] cucu 
[cu] cucu

[cicit] cicit

[buyut] orang tua laki-laki dan perempuan dari kakek

[kakek usang] orang tua laki-laki dan perempuan dari kakek

[tok wo] sapaan kakak laki-laki tertua dari kakek atau nenek

[tokngah] sapaan kakak laki nomor dua, nomor tiga dari kakek dan nenek

[nek wo] sapaan kakak perempuan tertua dari kakek dan nenek

[nekngah] sapaan kakak perempuan nomor dua atau nomor tiga dari kakek dan nenek

[pak wo] kakak laki-laki dari ayah atau ibu ego

[wo] kakak laki-laki dari ayah atau ibu ego

[pakngah] kakak laki-laki nomor dua atau nomor tiga dari ayah atau ibu ego

[ngah] kakak laki-laki nomor dua atau nomor tiga dari ayah atau ibu ego

[pak cik] adik laki-laki dari ayah atau ibu ego

[cik] adik laki-laki dari ayah atau ibu ego

[paksu] adik bungsu laki-laki dari ayah atau ibu ego

[acu] adik bungsu laki-laki dari ayah atau ibu ego

[mak wo] kakak perempuan paling tua dari ayah atau ibu ego

[wo] kakak perempuan paling tua dari ayah atau ibu ego

[makngah] kakak perempuan nomor tengah (2 atau 3) dari ayah atau ibu ego

[ngah] kakak perempuan nomor tengah (2 atau 3) dari ayah atau ibu ego

[mak cik] adik perempuan dari ayah atau ibu ego

[cik] adik perempuan dari ayah atau ibu ego

[mak su] adik perempuan bungsu dari ayah atau ibu ego

[acu] adik perempuan bungsu dari ayah atau ibu ego
1.1.2 Leksikon kekerabatan yang bersifat afinal/hubungan perkawinan

Leksikon kekerabatan yang yang bersifat afinal adalah hubungan kekerabatan yang berasal karena pernikahan.

[laki] suami

[urang bini] istri

[ipar] ipar

[abang ipar] acuan untuk jenis laki-laki yang menikah dengan kakak perempuan ego

[ayuk ipar]acuan untuk jenis perempuan yang menikah dengan kakak lakilaki ego

[mertue/mertua] mertua

[menantu] menantu

[bisan/besan] besan

1.1.3 Sejajar ego

[abang] saudara kandung kakak laki-laki

[bang] saudara kandung kakak laki-laki

[ayuk] saudara kandung kakak

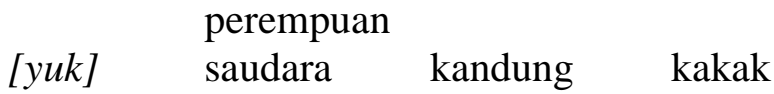

3.1.3 di atas ego

[bak] ayah

[bapak] ayah

[bapa] ayah

[mak] ibu

[ibu] ibu

[pak wo] kakak laki-laki dari ayah atau ibu ego

[wo] kakak laki-laki dari ayah atau ibu ego

[pak ngah] kakak laki-laki nomor dua atau nomor tiga dari ayah atau ibu ego

[ngah] kakak laki-laki nomor dua atau nomor tiga dari ayah atau ibu ego

[pak cik] adik laki-laki dari ayah atau ibu ego

[cik] adik laki-laki dari ayah atau ibu ego

[pak su] adik bungsu laki-laki dari ayah atau ibu ego

[acu] adik bungsu laki-laki dari ayah atau ibu ego

[mak wo] kakak perempuan paling tua dari ayah atau ibu ego

[wo] kakak perempuan paling tua dari ayah atau ibu ego 
[mak ngah]kakak perempuan nomor tengah (2 atau 3) dari ayah atau ibu ego

[ngah] kakak perempuan nomor tengah (2 atau 3) dari ayah atau ibu ego

[mak cik] adik perempuan dari ayah atau ibu ego

[cik] adik perempuan dari ayah atau ibu ego

[mak su] adik perempuan bungsu dari ayah atau ibu ego

[acu] adik perempuan bungsu dari ayah atau ibu ego

1.5 di bawah ego

[anak] anak dari ego/saya (sebagai orang tua)

[nak] anak dari ego/saya (sebagai orang tua)

[cucu] cucu

[cu] cucu

[cicit] cicit

3.2 Hubungan Peran dan Makna Leksikon

Kekerabatan Masyarakat Melayu

Bangka Dialek Pangkalpinang

3.2.1 Leksikon kekerabatan yang bersifat konsanguinal

[abang] 'kakak laki-laki' digunakan untuk menyapa kakak kandung

[bang] 'kakak laki-laki' dipakai untuk menyapa kakak kandung

[adek] 'adik laki-laki atau adik perempuan'

dipakai untuk menyapa adik [wo] kandung

[de'] 'adik laki-laki atau adik perempuan' digunakan untuk menyapa adik kandung

[bak] 'ayah' digunakan anak kandung laki-laki atau perempuan untuk sapaan dan acuan

[bapak] 'ayah' digunakan anak kandung laki-laki atau anak perempuan untuk sapaan

[ayah] 'ayah' digunakan anak kandung laki-laki atau anak perempuan untuk sapaan dan acuan

[mak] 'ibu' digunakan anak kandung lakilaki atau anak perempuan untuk sapaan dan acuan

[ibu] 'ibu' digunakan anak [paksu]

[buyut]

[tokngah]

[nek wo]

[pakwo]

[pak ngah]

[ngah]

[pak cik]

[cik]

kandung laki-laki atau anak perempuan untuk sapaan dan acuan

'orang tua laki-laki dan perempuan dari kakek' digunakan untuk sapaan dan acuan

'orang tua laki-laki dan perempuan dari kakek' digunakan untuk sapaan dan acuan

'sapaan kakak laki-laki tertua dari kakek atau nenek'

digunakan untuk sapaan dan acuan

'sapaan kakak laki nomor dua, nomor tiga dari kakek dan nenek' digunakan untuk sapaan dan acuan

'sapaan kakak perempuan tertua dari kakek dan nenek' digunakan untuk sapaan dan acuan

'sapaan kakak perempuan nomor dua atau nomor tiga dari kakek dan nenek' digunakan untuk sapaan dan acuan

'kakak laki-laki dari ayah atau ibu ego' digunakan untuk sapaan dan acuan

'kakak laki-laki dari ayah atau ibu ego' digunakan untuk sapaan dan acuan

'kakak laki-laki nomor dua atau nomor tiga dari ayah atau ibu ego' digunakan untuk sapaan dan acuan 'kakak laki-laki nomor dua atau nomor tiga dari ayah atau ibu ego' digunakan untuk sapaan dan acuan

'adik laki-laki dari ayah atau ibu ego' digunakan untuk sapaan dan acuan

'adik laki-laki dari ayah atau ibu ego' digunakan untuk sapaan dan acuan

'adik bungsu laki-laki dari ayah atau ibu ego' digunakan untuk sapaan dan acuan 
[acu]

[makwo]

[wo]

[ngah]

[makngah] 'kakak perempuan nomor tengah (2 atau 3) dari ayah atau ibu ego' digunakan untuk sapaan dan acuan

'kakak perempuan nomor tengah (2 atau 3) dari ayah atau ibu ego' digunakan untuk sapaan dan acuan

[mak cik] 'adik perempuan dari ayah atau ibu ego' digunakan untuk sapaan dan acuan

[cik] 'adik perempuan dari ayah atau ibu ego' digunakan untuk sapaan dan acuan' digunakan untuk sapaan dan acuan

[mak su] 'adik perempuan bungsu dari ayah atau ibu ego' digunakan untuk sapaan dan acuan

[acu] 'adik perempuan bungsu dari ayah atau ibu ego' digunakan untuk sapaan dan acuan

3.2.2 Leksikon Kekerabatan yang Bersifar Afinal

[laki] 'suami' digunakan untuk sapaan dan acuan

[bini] 'suami' digunakan untuk sapaan dan acuan

[mertue/mertua] 'mertua' digunakan untuk sapaan dan acuan

[bisan/besan] 'besan' digunakan untuk sapaan dan acuan

3.2.3 Sejajar Ego

[abang]'saudara kandung kakak laki-laki' digunakan untuk sapaan dan acuan

[bang] 'saudara kandung kakak laki-laki' digunakan untuk sapaan

[ayuk] 'saudara kandung kakak perempuan' digunakan untuk sapaan dan acuan [yuk] 'saudara kandung kakak perempuan' digunakan untuk sapaan

[adek] 'saudara kandung laki-laki atau saudara perempuan' digunakan untuk sapaan dan acuan

[de?] 'saudara kandung adik laki-laki atau perempuan' digunakan untuk sapaan

3.2.4 di atas ego

[bak] 'ayah' digunakan anak kandung laki-laki atau perempuan untuk sapaan dan acuan

[bapak] 'ayah' digunakan anak kandung laki-laki atau anak perempuan untuk sapaan

[ayah] 'ayah' digunakan anak kandung laki-laki atau anak perempuan untuk sapaan dan acuan

[mak] 'ibu' digunakan anak kandung lakilaki atau anak perempuan untuk sapaan dan acuan

[ibu] 'ibu' digunakan anak kandung lakilaki atau anak perempuan untuk sapaan dan acuan

[buyut] 'orang tua laki-laki dan perempuan dari kakek' digunakan untuk sapaan dan acuan

[kakekusang] 'orang tua laki-laki dan perempuan dari kakek' digunakan untuk sapaan dan acuan

[tok wo] 'sapaan kakak laki-laki tertua dari kakek atau nenek'

digunakan untuk sapaan dan acuan

[tok ngah] 'sapaan kakak laki nomor dua, nomor tiga dari kakek dan nenek' digunakan untuk sapaan dan acuan

[nek wo] 'sapaan kakak perempuan tertua dari kakek dan nenek' digunakan untuk sapaan dan acuan

[nek ngah] 'sapaan kakak perempuan nomor dua atau nomor tiga dari kakek dan nenek' digunakan untuk sapaan dan acuan

[pak wo] 'kakak laki-laki dari ayah atau ibu ego' digunakan untuk sapaan dan acuan 
[wo] 'kakak laki-laki dari ayah atau
ibu ego' digunakan untuk
sapaan dan acuan

[pakngah] 'kakak laki-laki nomor dua atau nomor tiga dari ayah atau ibu ego' digunakan untuk sapaan dan acuan

[ngah] 'kakak laki-laki nomor dua atau nomor tiga dari ayah atau ibu ego' digunakan untuk sapaan dan acuan

[pak cik] 'adik laki-laki dari ayah atau ibu ego' digunakan untuk sapaan dan acuan

[cik] 'adik laki-laki dari ayah atau ibu ego' digunakan untuk sapaan dan acuan

[paksu] 'adik bungsu laki-laki dari ayah atau ibu ego' digunakan untuk sapaan dan acuan

[acu] 'adik bungsu laki-laki dari ayah atau ibu ego' digunakan untuk sapaan dan acuan

[makwo] 'kakak perempuan paling tua dari ayah atau ibu ego' digunakan untuk sapaan dan acuan

[wo] 'kakak perempuan paling tua dari ayah atau ibu ego' digunakan untuk sapaan dan acuan

[makngah] 'kakak perempuan nomor tengah (2 atau 3) dari ayah atau ibu ego' digunakan untuk sapaan dan acuan

[ngah] 'kakak perempuan nomor tengah (2 atau 3$)$ dari ayah atau ibu ego' digunakan untuk sapaan dan acuan

[makcik] 'adik perempuan dari ayah atau ibu ego' digunakan untuk sapaan dan acuan

[cik] 'adik perempuan dari ayah atau ibu ego' digunakan untuk sapaan dan acuan' digunakan untuk sapaan dan acuan

[maksu] 'adik perempuan bungsu dari ayah atau ibu ego' digunakan untuk sapaan dan acuan [acu] 'adik perempuan bungsu dari ayah atau ibu ego' digunakan untuk sapaan dan acuan

[atok] 'kakek, orang tua laki-laki dari ayah atau ibu' digunakan untuk sapaan dan acuan

[tok] 'kakek, orang tua laki-laki dari ayah atau ibu' digunakan untuk sapaan

[kakek] 'kakek, orang tua laki-laki dari ayah atau ibu' digunakan untuk sapaan dan acuan

[kek] 'kakek, orang tua laki-laki dari ayah atau ibu' digunakan untuk sapaan

[ninek] 'nenek, orang tuan laki-laki perempuan dari ayah atau ibu' digunakan untuk sapaan dan acuan

[nek] 'nenek, orang tuan laki-laki perempuan dari ayah atau ibu' digunakan untuk sapaan

\subsection{5 di bawah ego}

[anak] 'anak dari ego' digunakan untuk acuan dari anak laki-laki atau anak perempuan

[nak] 'anak' digunakan untuk sapaan

[сиси] 'cucu' digunakan untuk acuan

[cu] 'cucu' digunakan untuk sapaan

'cicit' digunakan untuk sapaan dan acuan

\section{SIMPULAN}

Berdasarkan pemaparan hasil penelitian leksikon kekerabatan etnik Melayu Bangka di Kota Pangkalpinang maka penutur atau pengguna bahasa Melayu Bangka dapat dikategorikan pada dua hal, yang pertama bersifat konsanguinal dan yang kedua bersifat afinal. Konsanguinal mengacu pada leksikon yang menunjukkan adanya hubungan pertalian darah, sedangkan afinal mengacu pada hubungan yang disebabkan karena pernikahan. Masing-masing tersebut dikelompokkan menurut jenis kelamin, tingkat generasi, garis keturunan, dan umur. 


\section{DAFTAR PUSTAKA}

Burling, R. (1970). Mans Many Voices, Language and Its Context. Holt Reinhart and Winston Inc. New York.

Casson, R. W. (1981). Language, Culture, and Cognition. New York. Macmillan Publishing. Co. Inc.

Folley, A.W. (1997). Anthropological Linguistics: An Introduction. Oxford, England: Blackwell.

Hoijer, H. (1954). Language in Culture. Chicago: Chicago Press Publisher Ltd.
Karamoy, O.H.S. (1997). Sistem Sapaan Bahasa Toutemboan. Manado: Tesis.

Karouw, S.S.M. (2011). Istilah Kekerabatan Bermakna Budaya dalam Bahasa Tobelo: Suatu Kajian Linguistik Antropologi. Manado: Tesis.

Lumempouw, Femmy. (2013) Leksikon Kekerabatan Melayu Manado. Jurnal Kajian Linguistik Tahun I, No. 1 Juni 2013. Program Magister Unsrat, ISSN 2338-4085 